\title{
Social Death through HIV and AIDS Stigmatization and Discrimination in Ghana: A Case Study of the Central Regional Hospital, Cape Coast, Ghana
}

\author{
Eric Koka ${ }^{1,2 *}$, Collins K. Ahorlu ${ }^{2}$, Dominic K. Agyeman ${ }^{3}$ \\ ${ }^{1}$ School of Public Health, University of Ghana, Legon, Ghana \\ ${ }^{2}$ Noguchi Memorial Institute for Medical Research, University of Ghana, Legon, Ghana \\ ${ }^{3}$ Department of Sociology and Anthropology, University of Cape Coast, Cape Coast, Ghana \\ Email: "ekoka@noguchi.mimcom.org, "erickoka2000@yahoo.com, cahorlu@noguchi.mimcom.org, \\ dkofiagyeman@yahoo.com
}

Received July 30 $0^{\text {th }}$, 2013; revised August 30 ${ }^{\text {th }}$, 2013; accepted September $7^{\text {th }}$, 2013

Copyright (c) 2013 Eric Koka et al. This is an open access article distributed under the Creative Commons Attribution License, which permits unrestricted use, distribution, and reproduction in any medium, provided the original work is properly cited.

\begin{abstract}
Stigmatization of and discrimination against People Living with the Human Immunodeficiency Virus (PLHIV) and Acquired Immunodeficiency Syndrome (AIDS) are increasingly recognized as the single greatest challenge to slowing the spread of HIV and partly the cause of the increased death rate particularly in Africa and Ghana to be specific. The purpose of the study was to identify the causes and effects of stigmatization of and discrimination against PLHIV visiting the Central Regional Hospital of Ghana for treatment and care. The research was conducted with a sample size of 120. Purposive and convenient/accidental sampling techniques were used to select respondents for the study. The study revealed that some people in Ghana stigmatize PLHIV because of the misconceptions they have about the modes of HIV transmission, the myths surrounding HIV and AIDS as well as their socio-cultural backgrounds and orientations. These stigmatizing behaviors towards PLHIV have serious health, social and psychological effects on them in particular and the society at large. Based on the results of the study, it is recommended that there should be an intensification of education on HIV and AIDS through the media. This would make the population in Ghana more knowledgeable about the disease, which may help to reduce stigmatization of and discrimination against persons living with HIV.
\end{abstract}

Keywords: Human Immunodeficiency Virus (HIV); Acquired Immunodeficiency Syndrome (AIDS); Stigmatization; Discrimination; Persons/People Living with HIV and AIDS (PLHIV)

\section{Background}

HIV and AIDS in Ghana were first recorded in 1986, mainly among women who had travelled outside the country and since then the epidemic has been growing steadily (GAC, 2011a). However, there has been some decline in recent years (GAC, 2011b). In the light of experience elsewhere in Africa, it is necessary to understand the potential effects of an HIV and AIDS epidemic (GAC, 2011c). Transmission of HIV in the country is largely due to heterosexual contact, mother-to-child transmission, transmission through transfusion with contaminated blood and through the sharing of contaminated skin-piercing instruments such as needles, blades, etc. (GSS, 1998). According to the 1998 Ghana Demographic Health Survey Report, although HIV and AIDS awareness is very high with $97 \%$ of women and $99 \%$ of men hearing of the epidemic, personal risk perception is low, as $54 \%$ women and $58 \%$ men believe that they have no chance of contracting HIV (GSS, 2011).

Ghana acknowledged the public health threat of AIDS and started to inform people about it long before the first case was diagnosed in the country in March 1986. The major reason for

*Corresponding author. initiating educational campaigns was that people should not be allowed to die of ignorance (Addo-Yobo et al., 1992). From the very beginning, the HIV epidemic has been accompanied by fear, ignorance and denial, leading to stigmatization of and discrimination against PLHIV and their family members $(\mathrm{MoH}$, 2008). The result was that those, who did not know their HIV sero-status, were afraid of having to face stigmatization and discrimination, if they should be diagnosed of the infection and therefore, they were not responding to voluntary testing and treatment campaigns $(\mathrm{MoH}, 2008)$. In view of the challenges that PLHIV faces in terms of stigmatization and discrimination, HIV-related stigma is increasingly recognized as the single greatest challenge to slowing down the spread of the disease (Varni et al., 2012).

In spite of increasing awareness that stigmatization could have negative impact on HIV and AIDS control, very little is done by way of policy and programs to reduce stigmatization largely because efforts are impeded by the dearth of information on HIV-related stigma from the affected and infected points of views (Varni et al., 2012).

HIV and AIDS-related stigma and resulting discriminatory acts create circumstances that fuel the spread of HIV (UNAIDS, 
2010). Fear of being identified with HIV prevents people from taking a test to know their status or change their unsafe behaviors. A study conducted by the International Center for Research and Women (ICRW) in Botswana and Zambia found that stigma against HIV-positive people and fear of mistreatment prevented people from participating in voluntary counseling and testing (VCT) and programs to prevent mother-to-child transmission (MTCT) (Neuman et al., 2013). Stigma prevents individuals and communities from using all manner of HIV programs such as home-based care programs, health facilitybased programs or other support services (Neuman et al., 2013).

Ghana initially responded to HIV and AIDS as a health issue rather than a developmental issue. In this regard, the government directed the Ministry of Health $(\mathrm{MoH})$ to take the lead in efforts aiming at mitigating the impact of the epidemic. In 1987, the $\mathrm{MoH}$, therefore, established the National AIDS Control Program (NACP) to implement and coordinate the country's HIV and AIDS Program. This was later transformed into Ghana AIDS Commission. In addition, a National HIV and AIDS and STI policy was developed to guide the national response. The $\mathrm{MoH}$ through the NACP has spearheaded various strategies to contain and limit the spread of HIV infection and one way is by reducing fear, stigma and discrimination through advocacy and educational campaigns, however, this did not yield the desired results (Asante, 2010).

Having come to the realization that a multi-sectoral approach would be the best way of responding effectively to HIV and AIDS, the government threw a challenge to all stakeholders, i.e. governmental and non-governmental organizations, faith-based organizations, the private sector, etc. to get involved in the HIV and AIDS response activities. As a result, the Ministry of Education, for example, set out to provide adequate information on $\mathrm{HIV}$ and AIDS to students. It put in place several intervention strategies and the key among them is the School HIV-Alert Model, an initiative that seeks to give momentum to schoolbased control efforts through nationwide campaigns. The Ministry of Local Government and Rural Development also put in place decentralized response structures for HIV and AIDS at the District levels through the activities of the District Response Initiative (DRI) which was launched in 2000 (Asante, 2010).

Until recently, the involvement of the religious bodies was limited to initiatives coordinated through the health institutions of the Christian Health Association of Ghana. These efforts have largely been in the area of care and support. Over the past years, however, there has been rapid growth and positive involvement of Christians and Muslims organizations in the fight against the epidemic (Asante, 2010).

\section{Stigmatization-Conceptual Definition and Forms}

Stigmatization is generally defined as an "attribute that is deeply discrediting" and it reduces the bearer "from a whole and usual person to a tainted discounted one" (Goffman, 1963). Stigmatization often leads to discrimination, which refers to any form of distinction, exclusion, or restriction affecting a person by virtue of personal characteristics (Li et al., 2013). Stigma is not unique to HIV and AIDS. It has been documented with other infectious diseases like tuberculosis, syphilis, and leprosy (Fields et al., 2013). Stigma is most frequently associated with diseases that have severe, disfiguring, incurable and progressive outcomes, especially when modes of transmission are perceived to be under the control of individual behavior. It is also common in diseases that are perceived to result from the transgression of social norms, such as socially unsanctioned sexual activity (Crandall et al., 1995).

Erving Goffman is widely credited for conceptualizing and creating a framework for the study of stigma. His explanation of stigma focuses on the public's attitude toward a person who possesses an attribute that falls short of societal expectations. These are beliefs that are transmitted through lineages and equally contaminated by all members of a family (Goffman, 1963). From the foregoing definitions, it has been realized that stigmatization is a process. Stigmatization, therefore, describes a process of devaluation rather than a thing. Much of the HIV and AIDS-related stigma builds upon and reinforces negative thoughts.

PLHIV are often seen as people, who have been infected because they did something wrong. Often these "wrong doings" are linked to sex or something illegal or what is socially frowned upon. Men who become infected with HIV may be seen as homosexuals, bisexuals or people who have had sex with commercial sex workers. Women infected with HIV are viewed either as commercial sex workers or as women who have been "promiscuous". Families and communities often perpetuate stigma and discrimination partly because it is convenient to blame those who have been infected with HIV first $(\mathrm{MoH}$, 2008).

\section{Rationale}

The appearance of HIV in 1981 has created fear and panic among the populations of the world. This has resulted in stigmatization of and discrimination against HIV infected persons. Evidence from AIDS research in the last decade has reinforced the view that the state of health of any group of people is related to its living conditions, the socio-cultural context in which people are socialized, and the respect for basic rights of the individual (Mann, 1994).

As the disease enters its fourth decade and more people get infected, there is the need to understand the psycho-social coping mechanisms adopted by PLHIV. This is important in Ghana where counseling is not well-developed or incorporated into the modern health care system (Bosu et al., 2009). There is, therefore, the need for studies to look at the effects of stigmatization on HIV-infected persons and the society at large so that measures can be put in place for its control. The study examined the extent to which people living with HIV/AIDS are stigmatized by others. The examination was done by considering factors as misconceptions, knowledge of HIV/AIDS, fear of HIV/AIDS, and bias (discrimination) in health care delivery.

\section{Objectives}

The goal of this study was to determine the different opinions and beliefs that individuals have about PLHIV and the reasons underlying the stigmatization of and discrimination against PLHIV. Specifically, the study was designed to examine the causes and effects of stigmatization on PLHIV and measures which could be taken to reduce stigmatization of and discrimination against PLHIV.

\section{Methods}

\section{Study Area}

According to the 2010 Population and Housing Census data, Central Region had an estimated population of 2.2 million and 
growth rate of about $3.1 \%$ per annum (GSS, 2011). The region is made up of 20 districts covering a coastal and forest zones. A larger proportion of the populations are fishermen and crop farmers. According to the 2011 HIV Sentinel Surveillance (HSS) report, Cape Coast, the Central Regional capital, recorded Ghana's highest HIV rate, leaping from a prevalence of 2.2 percent in 2010 to 9.6 percent in 2011. According to the report, the Central Region also recorded the highest HIV prevalence of 4.7 percent in 2011, indicating more than a 100 percent increase from 1.7 percent in 2010 (GAC, 2011).

The Central Regional Hospital was chosen for the study to gather data from PLHIV, health service providers and visitors to the hospital, who did not know their HIV status because it is the only hospital in the region with a specialized clinic (fevers unit) for HIV and AIDS treatment, care and support.

The HIV and AIDS situation in the region is said to be threatening because it is believed that the number of infected but unidentified clients could be quite high considering the fact that there are two universities, a polytechnic, teacher and nurses training colleges and numerous senior high schools in the region, especially in Cape Coast, which attracts people from all over the country including tourists who are sexually active to these facilities. In the light of all these, the $\mathrm{MoH}$ and the Ghana Health Service (GHS) in their efforts to curb the spread of the disease through blood screening, pre-post test counseling and clinical management, have set up an HIV and AIDS Clinic (Fevers Unit). The Unit has embraced the government initiative of reaching out to the people living with HIV and AIDS. Hence, the Unit has been named New Hope Express ("Nyaakokoduro", meaning "be bold"). This is because the staff of the Unit are expected to give hope to the "hopeless" by providing adequate treatment, care and support to them, so that even if they come face-to-face with death, they die in peace and dignity.

\section{Target Population and Sampling}

The population for the study included health care practitioners in the Central Regional Hospital, PLHIV and their family members as well as their friends. Two non-probability sampling techniques, namely purposive sampling and accidental sampling were employed. Purposive sampling technique was employed to select 30 PLHIV who were attending clinic; 30 caretakers (relatives, friends and loved ones of PLHIV) and ten nurses who usually attend to PLHIV in the Fevers Unit. Convenient or accidental sampling technique was used to select 50 visitors to the hospital who did not know their HIV status. The total sample size for the study was, therefore, 120 .

\section{Data Collection Instruments}

Two data collection instruments were used. These were indepth interview and questionnaire.

\section{In-Depth Interview}

An in-depth interview guide was developed and pre tested before it was used to interview PLHIV and their caretakers regarding their knowledge about HIV and AIDS as well as their perceptions about stigmatization of and discrimination against PLHIV, their families and friends.

\section{Questionnaire Survey}

Questionnaire was administered to people who had gone to visit relatives and friends, who had been hospitalized at the hospital. The nurses who took care of the PLHIV at the Fevers Clinic were given questionnaires to complete at their own convenience and return later. All questionnaires were retrieved from the visitors who came to the hospital and the nurses at the hospital. The questionnaire was pre tested for consistency and reliability for the main study.

\section{Data Analysis}

The data collected were edited, coded, and analyzed for common themes. The analysis was done using the Statistical Product for Service Solution (SPSS) computer software package (Version 16.0 for Microsoft Windows). Results are presented descriptively, incorporating both quantitative and qualitative findings.

\section{Ethical Review}

The study was approved by the Ethical Review Committee of the Ministry of Health, Cape Coast, Ghana and the Ethics Committee of the Central Regional Hospital, Cape Coast. Respondents gave verbal consent that was witnessed by two health personnel from the Fevers Unit of the hospital. Since the study did not pose any major threat to the interviewees, who, prior to the start of all interviews, were informed about the study aims, their rights to withdraw participation from the study, the intended use of findings to reduce HIV-related stigma and also for publication in academic journals and reports. The researcher reassured all interviewees of anonymity.

\section{Results}

\section{PLHIVs' Source of Information of HIV Status}

All the 30 PLHIV interviewed said that they were informed of their HIV positive status when they went to the hospital either for diagnosis and treatment of ailments other than HIV or for voluntary counseling and testing (VCT). The findings show that twenty (66.7\%) of them went to the hospital as a result of frequent fever; five (5) representing $16.7 \%$ as a result of frequent coughing; two (2) representing $6.7 \%$ because of frequent diarrhea; another group of two (2) also representing $6.7 \%$ because skin rashes; and one (1) representing 3.3\% because of voluntary counseling and testing.

The following are some of the responses they gave to the question: "how did you know your HIV status?"

- I had some rashes and fever and went to the hospital for a test and scan. It was noted there that I had HIV (a young lady, in-depth interview);

- I was in Accra and started coughing seriously so I went for tests, but the first lab found nothing. After a lab test at Apam, I was diagnosed of HIV (male, in-depth interview);

- It all started when I returned from Nigeria in the 80s. I started falling ill frequently with severe cough. I went to hospitals for treatment until recently when a test conducted declared I had HIV (female, in-depth interview);

- I used to cough and had blood in the phlegm that came out, so I went to the hospital and was diagnosed of HIV (female, in-depth interview).

The most common opportunistic illness/infection often diagnosed in HIV-infected persons in Ghana is tuberculosis which goes with severe cough. Only one out of the thirty respondents went to the hospital for voluntary counseling and testing for 
HIV, an indication that voluntary testing might be very low in the Central Region. Various reasons may account for this low level of voluntary testing in the Central Region; however it has been argued that the fear of stigmatization prevents people from going for voluntary counseling and testing in HIV.

\section{Source of General Information about HIV and AIDS by Persons, Who Did Not Know Their Status}

All the 50 respondents, who did not know their HIV status, were aware of HIV and AIDS. 37 of them representing 74 percent indicated that their source of information of HIV was the media and seven (7) representing 14 percent stated the school as their source of information; as shown in Table 1 below.

\section{Nurses and Types of Healthcare They Gave to PLHIV}

Out of the ten nurses interviewed, five (5) representing 50 percent said they gave solely medical care to PLHIV visiting their facility; three (3) indicated that they took their clients through counseling; and two (2) representing 20 percent indicated medical care and counseling. Qualitative narratives suggested that some of the nurses were scared of being infected and therefore treated their clients with caution. The following representative narratives support this position:

- I render quality healthcare to them with great caution to avoid infecting myself with HIV;

- I treat them just as any patient but with care;

- I don't want to be infected. You have to make sure you do not infect yourself (In-depth interview with a nurse).

\section{People Living with HIV and AIDS on Stigmatization}

To the question, "do some people stigmatize you because of your HIVIAIDS status?” Out of the 30 PLHIV interviewed, 20 representing $66.7 \%$ said "no" to the question, whiles 10 representing 33.3\% answered the question in the affirmative.

Respondents, who felt rejected, stigmatized and discriminated against reported going through a lot of psychological trauma and this affected their state of health negatively, as stated in the following narratives:

- Because my family rejected me;

- My nieces and nephews do not even want to use things like utensils and cups that belong to me;

- Some people who know my status refuse to interact with me;

- Through negative attitude when we were quarreling;

- I get worried when I go through this discrimination from friends;

- In fact these actions make me have sleepless nights and I am very lean and pale. Initially, I was thinking and always crying so it really affected me but I do not bother now;

- It is affecting me seriously, psychologically and healthwise;

- I have lost my self-esteem and identity;

- It was affecting me when my mum was avoiding me (An indepth interview session with a female Aids patient).

PLHIV, who were well-received and treated positively reported on their feelings as follows:

- I am fine because my wife treats me well;

- Since people are nice to me, I am fine;

- The love and care and concern they show rather make me healthy and strong;
Table 1.

Source of general information about HIV and AIDS of persons, who did not know their status.

\begin{tabular}{ccc}
\hline & Frequency & Percent \\
\hline School & 7 & 14.0 \\
Print and electronic media & 37 & 74.0 \\
Friends & 4 & 8.0 \\
Books & 1 & 2.0 \\
Parents & 1 & 2.0 \\
Total & 50 & 100.0 \\
\hline
\end{tabular}

- Their deeds help me to be healthy (in-depth interview with a male aids patient).

Some PLHIV reported that they did not feel comfortable when they were in the company of people, who had not been tested, whiles others reported that they felt comfortable. Fifteen (50\%) PLHIV interviewed said they either felt ashamed or shy when they were in the company of people, who had not been tested.

\section{Drinking or Not Drinking from the Same Cup}

When persons who did not know their HIV status were asked "whether or not they would share the same cup with PLHIV", 21 (42\%) answered the question in the affirmative and maintained that they could not be infected through the sharing of cups. Ten (20\%) said they would not drink from the same cup used by PLHIV because of the fear of being infected. Nine (18\%) of the respondents said they would not drink from the same cup so as to prevent getting infected. These positions are confirmed by representative narratives below.

- The person might have a cut in the mouth and might transfer the virus from the mouth to the cup and I might get infected;

- Prevention is better than cure. Anything can happen by sharing items like cup with them;

- It is dangerous to drink from a patient's cup because there can be exchange of body fluids;

- Because I am afraid of getting infected;

- Because of fear (In-depth interview with male respondent who did not know his HIV status).

\section{Discussion}

This study looked at the causes and effects of stigmatization on PLHIV. The study area was the Central Regional Hospital of Ghana. The main finding of the study was that, almost all HIV positive respondents reported having severe cough and rashes before being diagnosed of HIV. Again the study revealed that people were reluctant to go for voluntary counseling and testing for HIV. This is an indication that voluntary testing is very low in the Central Region. Various reasons may account for this low level of voluntary testing in the Central Region. However, it has been argued that the fear of stigmatization prevents people from going for voluntary counseling and testing in HIV (Nzamb et al., 2009). The study also shows the important role the mass media plays in information dissemination in Ghana since the majority of respondents got informed about HIV/ AIDS through the mass media. 
Available research and literature (GAC, 2011) showed that the mode of health care delivery to PLHIV also leads to stigmatization and discrimination. Findings in this study suggest elements of discrimination against PLHIV by health workers who indeed must be at the fore front of creating a positive awareness and attitude to PLHIV. Findings show that the mode of health care delivery to PLHIV patients by some health practitioners may lead to stigmatization because of their fear of being infected.

Findings show that stigmatization of and discrimination against PLHIV has reduced them to the state of "social" death, which may prevent others from taking tests to know their status to adopt healthy behavior as a way of preventing the spread of the disease. It has been argued that due to the reactions of others as well as the internalized self-feelings (Annemiek Schadé et al., 2013) stigmatized persons' life chances and opportunities are lessened, they are set apart from others. They are considered to be inferior and represent a danger to society. All these lead to social rejection and social isolation (Goffman, 1963). These findings confirm the view that stigmatized persons often lose their social status (Crocker et al., 1991); they are discounted and discredited or reduced in the minds of others from being whole and acceptable individuals. So, if you have AIDS you "die" twice because the first thing that kills you is being lonely when everyone discriminates against you long before your biological death.

\section{Conclusion}

Stigmatization of and discrimination against People Living with HIV and AIDS are complex and interrelated phenomena caused by multiplicity of factors, which could be broadly categorized as misconceptions due to lack of knowledge of HIV and AIDS, fear of HIV and AIDS (reactions) and the mode of health care delivery to People Living with HIV and AIDS. An important revelation from the study was that many People Living with HIV and AIDS did not disclose their status to their relatives and friends because they feared of being stigmatized and discriminated against. The study also found out that stigmatization and discrimination undermine efforts at AIDS prevention because fear of the reactions of others prevents people from finding out whether or not they are infected. In effect, many people get infected with HIV and continue to engage in risky sexual and other behaviors with those who are "not infected" and thereby putting them at risk. Findings discussed in this paper showed the persistency of HIV and AIDS related misconceptions which require equally consistent health promotion and education among both care providers and the general public.

\section{Weakness of the Study}

The main weakness of this study was that, it was conducted in only one hospital. For this reason the results cannot be generalized. However, the qualitative narratives of the interviewees indicated their actual feelings.

\section{Competing Interests}

The authors hereby declare that they have no competing interests.

\section{Authors' Contributions}

At the conception, design and implementation, and data collection stages of this paper EK, CKA, and DKA were all involved. After the collection of the data, EK did the analysis, after which all the three authors again collectively wrote the paper, proofread and finalized it.

\section{Acknowledgements}

We are grateful to the staff of the Central Regional Hospital for assisting us to complete this study. We also thank our respondents, both the infected and the affected, who shared their experiences with us by participating in the study. Without them we could not have carried out this study.

\section{REFERENCES}

Addo-Yobo, E. O., \& Lovel, H. (1992). Hospital users' knowledge about blood transfusion and awareness and attitudes towards AIDS/ HIV infection in a region in Ghana. Journal of Tropical Pediatrics, 38, 94-95. http://dx.doi.org/10.1093/tropej/38.2.94

Asante, F. A. (2010). National AIDS Spending Assessment (NASA): Level and flow of resources and expenditure to confront HIV and AIDS, DRAFT. Accra: Institute of Statistical Social and Economic Research (ISSER), University of Ghana, UNAIDS Ghana Country Office, Ghana AIDS Commission.

Bosu, W., Yeboah, K., Rangalyan, G., Atuahene, K., Lowndes, C., Stover, J. et al. (2009). Modes of HIV transmission in West Africa: Analysis of the distribution of new HIV infections in Ghana and recommendations for prevention. Accra: Ghana AIDS Commission.

Crandall, C. S., \& Moriarty, D. (1995) Physical illness stigma and social rejection. British Journal of Social Psychology, 34, 67-83. http://dx.doi.org/10.1111/j.2044-8309.1995.tb01049.x

Crocker, J., Major, B., \& Steele, C. (1991). Methods for understanding the 136 stigma of AIDS in the United States: A review and future directions. Houston: Rice University Press.

Fields, E. L., Bogart, L. M., Galvan, F. H., Wagner, G. J., Klein, D. J., \& Schuster, M. A. (2013) Association of discrimination-related trauma with sexual risk among HIV-positive African American men who have sex with men. American Journal of Public Health, 103, 875880. http://dx.doi.org/10.2105/AJPH.2012.300951

Ghana AIDS Commission (2011a). National HIV prevalence and AIDS estimates report.

Ghana AIDS Commission (2011b). Sentinel survey report, Accra, Ghana.

Ghana AIDS Commission (2011c). Status of the Ghana national HIV and AIDS response report.

Ghana Statistical Service (1998). Demographic and health survey, round 3. Accra: Ghana Statistical Service.

Ghana Statistical Service (GSS) (2011). Ghana Statistical Service (GSS) final report, 2010 population and housing census.

Goffman, E. (1963). Stigma: Notes on the management of spoiled identity. New York: Simon \& Schuster, Inc.

Li, M. J., DiStefano, A., Mouttapa, M., \& Gill, J. K. (2013) Biasmotivated bullying and psychosocial problems: Implications for HIV risk behaviors among young men who have sex with men. AIDS Care, 1-11. http://dx.doi.org/10.1080/09540121.2013.811210

Mann, J. (1994). Health and human rights. Health and Human Rights, 1, 6.

Ministry of Health (2008). National guidelines for the development and the implementation of HIV counseling and testing. Accra: Ministry of Health, Ghana Health Service, National AIDS Control Program.

Neuman, M., \& Obermeyer, C. M. (2013) Experiences of stigma, discrimination, care and support among people living with HIV: A four country study. AIDS and Behavior, 17, 1796-1808. http://dx.doi.org/10.1007/s10461-013-0432-1

Nzambi, K., Bevalot, M., Till, H., \& Dzokoto, A. (2009). Study on stig- 


\section{E. KOKA ET AL.}

ma and discriminatory attitudes and perceptions in Accra and Tema Metropolis in Ghana: How does the general adult population see most at risk populations and how do most at risk populations (MARP) see themselves in the context of HIV/AIDS in Ghana? Accra German Technical Cooperation.

Schadé, A., van Grootheest, G., \& Smit, J. H. (2013). HIV-infected mental health patients: Characteristics and comparison with HIV-infected patients from the general population and non-infected mental health patients. BMC Psychiatry, 13, 35.
UNAIDS (2010). United Nations general assembly special session on HIV/AIDS 09: Monitoring the declaration of commitment on HIV/ AIDS. Guidelines on construction on core indicators, 2010 reporting. Geneva: UNAIDS.

Varni, S. E., Miller, C. T., \& Solomon, S. E. (2012) Sexual behavior as a function of stigma and coping with stigma among people with HIV/AIDS in rural New England. AIDS and Behavior, 16, 23302339. 